\title{
Courtyards Design Variants and Its Functions in Malaysian Hospitals
}

\author{
Abdulbasit Almhafdy, Norhati Ibrahim, \\ Sabarinah Sh. Ahmad, Josmin Yahya \\ Faculty of Architecture, Planning and Surveying, \\ Universiti Teknologi MARA, 40450 Shah Alam, Selangor, Malaysia \\ mhf2000@msn.com
}

\begin{abstract}
The courtyard becomes a vital element that commonly applied in tropical buildings for its environmental, social and therapeutic potentials. However, effort to examine its usage and design variants is limited. This paper focuses on the application of courtyards in the context of Malaysian hospitals. Thirty-two courtyards were inventoried. Besides the courtyard functions, design variants were recorded in terms of its form and aspect ratio, courtyard orientation and physical features. The results revealed that the courtyards in the Malaysian hospitals buildings are creatively manipulated. The paper concludes with an outline of means to optimize a courtyard's microclimatic and healing performances.
\end{abstract}

Keywords: Courtyard function; design variants; hospitals; environmental aspect

eISSN: 2398-4295 @ 2016. The Authors. Published for AMER ABRA by e-International Publishing House, Ltd., UK.. This is an open access article under the CC BY-NC-ND license (http://creativecommons.org/licenses/by-nc-nd/4.0/). Peer-review under responsibility of AMER (Association of Malaysian Environment-Behaviour Researchers), ABRA (Association of Behavioural Researchers on Asians) and cE-Bs (Centre for Environment-Behaviour Studies), Faculty of Architecture, Planning \& Surveying, Universiti Teknologi MARA, Malaysia.

https://doi.org/10.21834/ajbes.v111.15 


\subsection{Introduction}

Courtyard is a building element that originated from the hot and dry regions (Edwards, Sibley, Hakmi, \& Land, 2006). In the tropic, the concept of courtyard form imported from the western countries rather than adapting and applying original and traditional concepts into modern courtyards, making the basic form, such as the doughnut shape, the dominant courtyard form in many Asian countries. In addition, many ancient courtyards in Arab countries have a clear indication that the design variants of courtyard have been designed and improved by the integration of social, cultural and environmental factors. The variations of the design variations such as area, number of floors, orientation, exposure, types of wall and many more were introduced to achieve successful oriented courtyard that respond to the human needs (Reynolds, 2002). This paper aims to describe the characteristics of courtyards applied within a hospital environment in Malaysia. This documentation is essential to serve as baseline information for future research on the impact of courtyard design variants on its environmental performances.

\subsection{Literature Review}

\subsection{Courtyard functions}

A courtyard is a common architectural feature that has been applied for thousands of years in many parts of the world particularly in houses. Courtyards were often the primary meeting places for specific purposes including gardening, cooking, working, playing, sleeping, or even in some cases as places to keep animals (Edwards et al., 2006).

Moreover, courtyard as a space can provide climatic as well as visual or acoustic protection. The courtyard geometry as well as its material makeup should be considered in the design stage in order to provide the highest level of thermal comfort possible (Berkovic, Yezioro, \& Bitan, 2012). In addition, the courtyard was developed to be climate responsive. Furthermore, courtyard can be utilized as an appropriate place for promoting natural, healing environment. According to Rust (2010), architects could place healing components of nature in courtyards within the building footprint, along with windows at the end of corridors to allow natural light to filter through to the public and private areas. Shade, water, trees and flowers, wind, pavement, and colours could induce positive effects towards the five senses of the human body.

In a Hong Kong study, Lau \& Yang (2004) introduced healing properties into a university campus (HKU) courtyards. They concluded that user experiences are enriched by introducing a courtyard such as: visual connection, privacy and security, transparency from indoor to outdoor. Findings from the case study at HKU showed that the gardens within a courtyard space has promoted social support, while the meditation garden was good for the academic ambience and helped to gain a good sense of control and privacy. The two courtyards should be distinguished from each other in terms of theme, use pattern, space and landscape design. As a library and reading rooms surround one of the courtyards, it was designed as a meditation garden with the theme of tranquillity. The other courtyard was close to the entrance of the complex. It played a more public role to encourage social interaction and support. 


\subsection{Courtyard configuration}

A courtyard is a common architectural feature that has been applied for thousands of years in many parts of the world particularly in houses. A courtyard does not have a fixed plan. Although the basic plan of a residential courtyard is usually rectangular or square, it can also be circular or curvilinear. Through history, this basic plan of the courtyard has been modified to fulfil many environmental aspects such as topography, site restriction, building orientation and function to create new shapes of courtyard such as U, L, T or Y (Reynolds, 2002; Wang, 2006). In addition, the design form of courtyard can be fully enclosed (four sided), semienclosed (three sided) or in some cases even two sided (Meir, Pearlmutter, \& Etzion, 1995). The courtyard form also has been applied in multistorey housing.

Certain investigations in the design form concept of courtyard have been done. It is clearly noticed that the design form can be played as a microclimate modifier to the environment. Many researchers have investigated the typical rectangular courtyard form in hot or temperate climate and its effect on the environmental performance. Aldawoud (2008) and Tablada et. al (2005), have recommended protection of the surface form and its surroundings from intense solar radiation and hot dusty wind as well as cross ventilation concept which have a direct impact on thermal comfort.

Meir, et al. (1995) studied the effect of three sided courtyard on the microclimate. The courtyard created better microclimatic condition; particularly when some variables are taken into consideration such as the orientation, attach volume and ventilation. Muhaisen (2006) studied the effect of a rectangular courtyard proportion (ratios and heights) at four different climatic locations. The simulation study explored the relationship between the courtyard form and shading performance and sun location and exposure. The optimum courtyard height to obtain a reasonable effect in summer and winter was found to be three storeys in hot humid climate, double storey in hot dry and temperate climate and one storey in cold climate. Hence, taller walls should surround courtyards in hotter climates and courtyards in colder climates could function with lower surrounding walls.

Muhaisen \& Gadi (2006) found that the deep courtyard form produced more internal shadow in summer while shallow form performed better in winter. The study has recommended an annual calculating ratio. However, for the daylight aspects, this solution is not recommended.

The potential of courtyards with less exposure to the sky (narrow) to act as passive cooling can be correlated with a building composition in terms of airflow rate and pattern in warm humid climates. The microclimate condition could be improved through naturally ventilated high mass residential buildings with internal courtyards (Rajapaksha, Nagai, \& Okumiya, 2003).

On the other hand, Muhaisen \& Gadi (2006) studied the polygonal courtyard forms (non typical form) and its shading performance to develop a shading calculation tool for courtyards. The study concluded that courtyard geometry and proportions have a significant influence on the shading produced on the internal surface. The sun location in the sky and the geometry of the courtyard can affect the shading condition within the courtyard. However, the research presented a computer based mathematical model but did not cover all the multi-sided courtyards. 


\subsection{Orientation}

In many cases, orientation of courtyard depends on the building layout. Variables that can positively affect the microclimate condition within the courtyard are sun location, wind direction, shading performance and solar gain (Almhafdy, Ibrahim, Ahmad, \& Yahya, 2013).

The orientation has also direct effect with the ventilation or wind speed. For instance, Meir, et al. (1995) has concluded that the correct orientation of courtyard can improve their thermal comfort; however, orienting them irrespective of solar angles and wind direction may create thermal discomfort.

\subsection{Wall enclosure}

Wall enclosure refers to all components that form the courtyard within the building and separate it's semi-enclosed conditioned space and fully closed condition space. Courtyard wall enclosure components such as walls, doors and windows need to be considered during the design stage.

Wall enclosure can play an important role in the microclimate condition of the courtyard through natural ventilation techniques. Wall enclosure can be manipulated by opening or closing of the apertures and by changing the window to wall ratio.

Aldawoud (2008) has attempted to investigate the thermal behaviour of courtyard buildings under different design conditions of glazing type and window to wall ratio. The courtyard wall enclosure materials (Al-Hemiddi \& Megren Al-Saud, 2001b; Sadafi, Salleh, Haw, \& Jaafar, 2011), colours and shading devices (Kim, Yang, \& Kang, 2014) are other options to look into when trying to improve the microclimate condition of the courtyard and the surrounding spaces.

\subsection{Natural elements within courtyard}

Placing natural elements within a courtyard would produce environmental benefits. For instance, Safarzadeh \& Bahadori (2005) found that trees, shrubs and flower plants (as a garden elements) within a courtyard can significantly affect the thermal comfort as they provide shaded area with the wall of the courtyard. Al-Hemiddi \& Megren (2001a) studied the effect of using water body (pond) and water spray within the courtyard on the thermal performance with control tent above the courtyard. It was found that the internal courtyard with a pool, tent and water spray during sunny hours provided significant cooling effect for the internal spaces surrounding the courtyard.

\subsection{Methodology}

Information from past researches on courtyard design variants and their impact on environmental performance were collated and used as the basis to formulate a courtyard descriptor checklist. The courtyards were inventoried using the prepared courtyard descriptor checklist, and walk-through observations were recorded.

\subsection{Checklist}

Table 1 shows the checklist that was used for the site inventory survey. The design variants of the courtyard were obtained according to the literature review presented in the introduction. 
In addition, other design variants (for example roof shading device) were added to the checklist.

Table 1: Checklist of design variants of courtyard

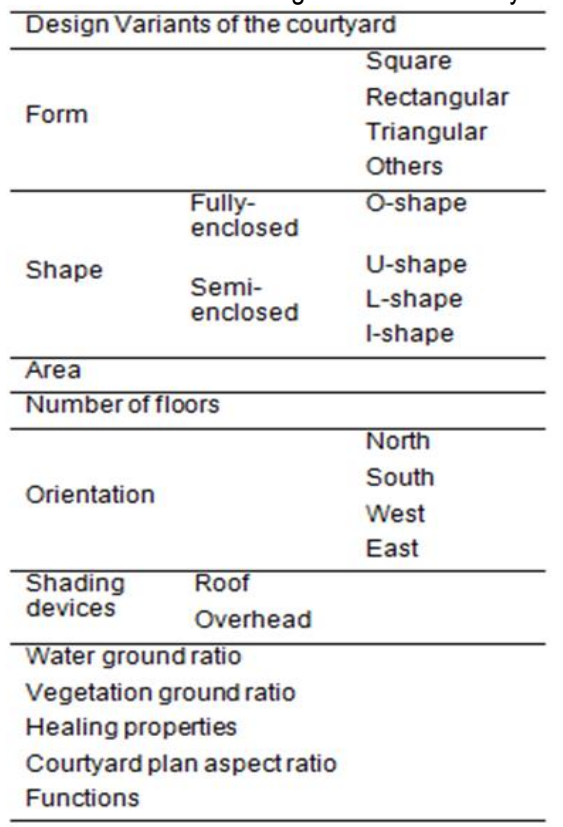

\subsection{Sites visit and observation}

The case studies were identified based on a discussion with an architect of the Public Works Department (PWD), responsible for the design and construction of government hospitals in Malaysia. A total of 32 courtyards in 19 Malaysian hospitals were inventoried. The data was collected using the courtyard descriptor checklist described earlier. The data collection process took six months as the hospitals are located at various parts of the peninsula. A one day walkthrough observation was conducted for each courtyard. Observation was made to record people's behavior within the courtyards and how that relate to the design situation.

\subsection{Results and Discussions}

The site survey also recorded factual data such as the courtyard functions, configuration, form and aspect ratio, courtyard orientation, physical features within the courtyard. It is observed that courtyards are common in the context of hospitals in Malaysia.

\subsection{Courtyard configuration in Malaysian hospitals}

The literature search identified that empirical research on the characteristics of courtyard applied in the Malaysian context are limited. The gap in knowledge here is evident as built 
courtyard is the least understood area of research. This paper found that the development of courtyard building has moved forward into the era of sustainability and green architecture.

Table 2 shows that courtyard configurations can be classified as cluster courtyard, open courtyard, complex courtyard and closed courtyard. The cluster courtyards are either multiple courtyard or spinal courtyard.

Table 2: Courtyard configuration in Malaysian hospitals

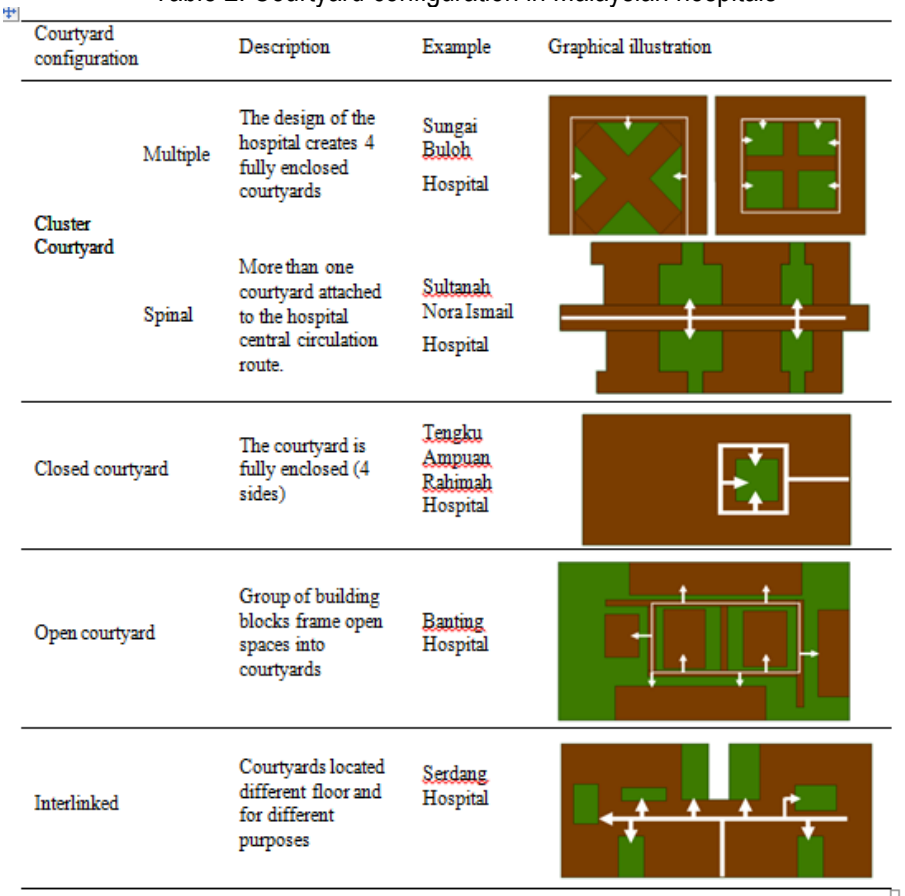

However, it was clear from the site visits that complex, multiple and closed courtyard are applied in the newer hospitals. Sultan Ismail Hospital in Johor Bahru is an example of a new hospital. The courtyard in the hospital is fully closed (O-shaped) with courtyard area of 2100 $\mathrm{m} 2$. Although the hospital has another three U-shaped courtyards, the O-shaped courtyard in the central area has many options of functions and activities such as for healing, waiting area, gardens and natural ventilation. Serdang Hospital has nine complex courtyards spread within the hospital complex. They are U-, O- and L-shaped and located at different floor.

The interlinked courtyards (cluster) types are found at Sungai Buloh Hospital in Sungai Buloh and Sultanah Bahiyah Hospital in Alor Star. The hospitals have almost the same layout (cross sign) that created the four triangular shaped courtyards in all directions.

The open and spinal courtyards are found in the older hospitals, built as early as 1970s. The buildings are aligned to form a minimal enclosure that celebrates the open courtyards. The spinal courtyards comprises more than one courtyards attached to the hospital central spine. Almost all cases, the courtyards are aligned with the hospital corridor. 


\subsection{Courtyard functions}

Courtyards has been utilized for many purposes through the history. In the Malaysian hospitals, the courtyards fulfil five main function. Courtyards were utilized as a garden, daylight element, ventilation system, playground and as a healingelement. Figure 1 shows that almost all the courtyards are utilized as gardens as well as for daylighting purposes. The potential of courtyards as a healing element is the least exploited where where 11 courtyards has healing elements. Human activities in the outdoor space within the courtyard are limited.

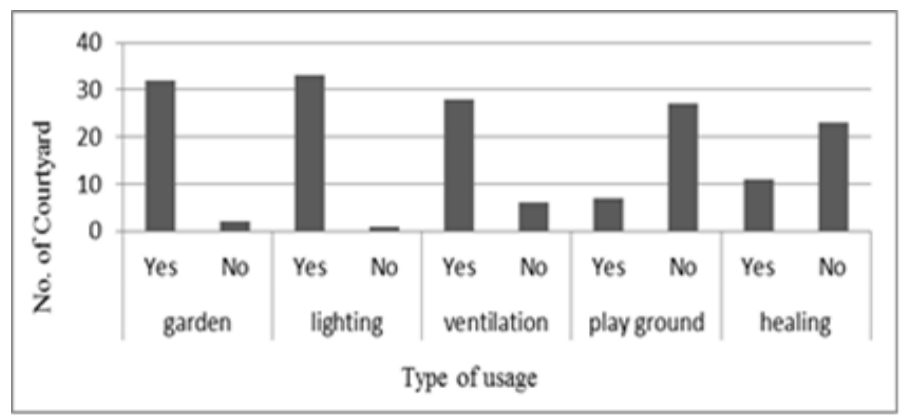

Figure 1: Courtyards functions in Malaysian hospitals

\subsection{Design variants of courtyard}

The design variants of courtyards, such as its shape, size and details of the enclosing structure or walls of a courtyard vary among regions and functions and in some cases among houses or building owners.

\subsubsection{Form and aspect ratio}

O-(fully enclosed) and U-shaped (semi enclosed) courtyards are the common courtyard shape. The courtyards are in square, rectangle or triangle shapes. Figure 2 shows that out of 34 courtyards, 23 are in 0-shape followed by 6 courtyards that have U-shape.

Most common geometric form is rectangular. Twenty-one courtyards in hospitals are in rectangular shape, and five square shaped courtyards. Four take the form of a triangle and four irregular shaped courtyards.

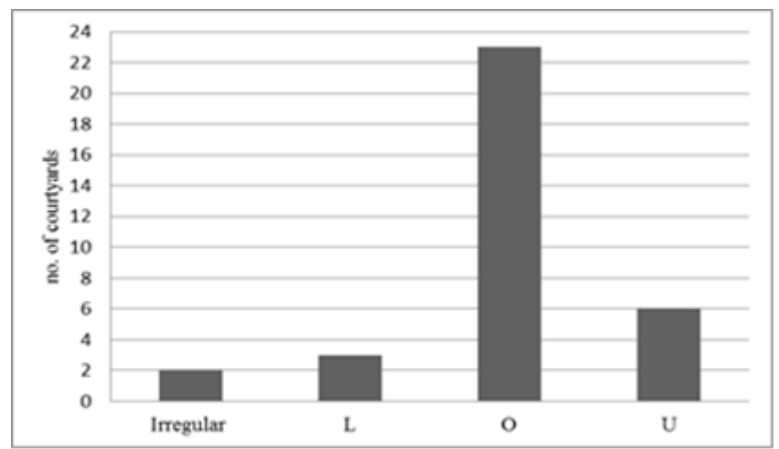

Figure 2: Courtyards functions in Malaysian hospitals 
The courtyard sizes are between 600 and $900 \mathrm{~m} 2$. The distribution of courtyard sizes is illustrated in Figure 3 . The aspect ratio of these courtyards is defined according to the width, length and height.

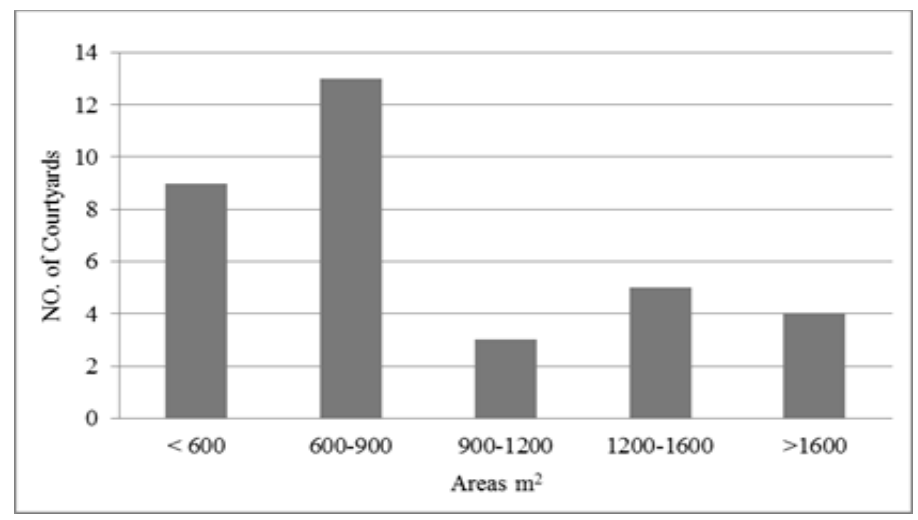

Figure 3: Courtyards sizes and areas

Figure 4 shows that eight courtyards have the highest wall in the west and east directions to prevent the courtyard from direct sun radiation. In contrast, other courtyards have the lowest walls in the west and east and that allowed more direct of solar radiation and thus, decreased the level of comfort.

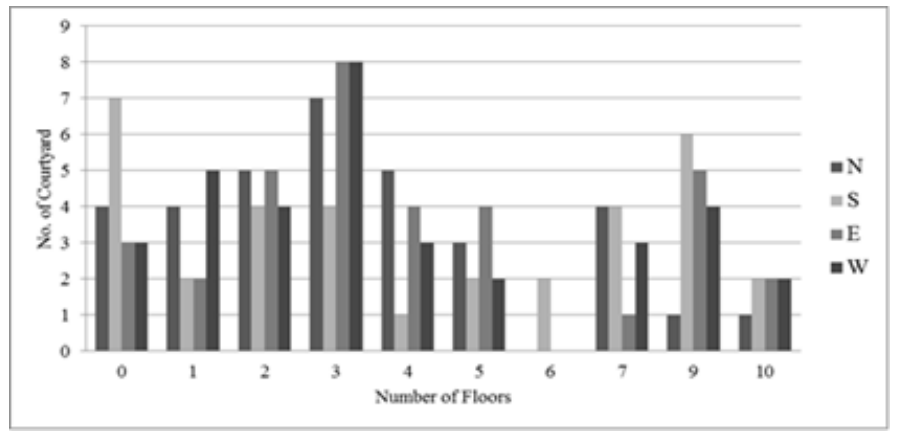

Figure 4: Number of floors in each directions North, South, East and West

\subsubsection{Orientation}

Another aspect of a courtyard that could influence its potential to serve best as a microclimatic modifier to the surrounding indoor and outdoor spaces is its orientation. While past studies have not verified as to which courtyard orientation performs best, the general rule is that the orientation of the courtyard orientation is to be elongated, facing north-south.

The survey recorded how the courtyard orientation factor was applied in practice (Figure 5). Fifteen of the courtyards are elongated in the East-West direction, and the remaining 13 elongated in the North-South direction. It is interesting that in some cases where the courtyards walls are elongated towards the severe east and west sun direction, higher building 
blocks are introduced. This serves to moderate the heat transfer into the courtyard spaces. For example in the case of the Hospital Tuanku Ja'afar, the courtyards are surrounded by building blocks of varying height. The higher blocks are located on the east and west side of the courtyards, standing at 10 -storey high.

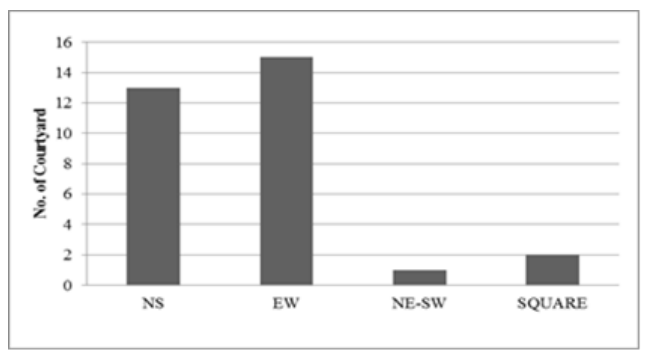

Figure 5: Orientation of courtyards in Malaysian hospitals

\subsubsection{Shading devices}

Cantilevered roofs and shading devices are considered as good tropical design elements. The survey recorded that one hospital introduced cantilevered roofs to protect the outdoor space within the courtyards. As shown in Figure 6a, observation on the frequent use of the outdoor courtyard space recorded that on the overall the number of users who entered and performed activities in the courtyard was around 10 per day. Introduction of cantilevered roofs within the courtyard space in the Hospital Banting (Figure 6b) may have made the outdoor space within the courtyard more comfortable that result in higher number of the hospital visitors using the courtyard.

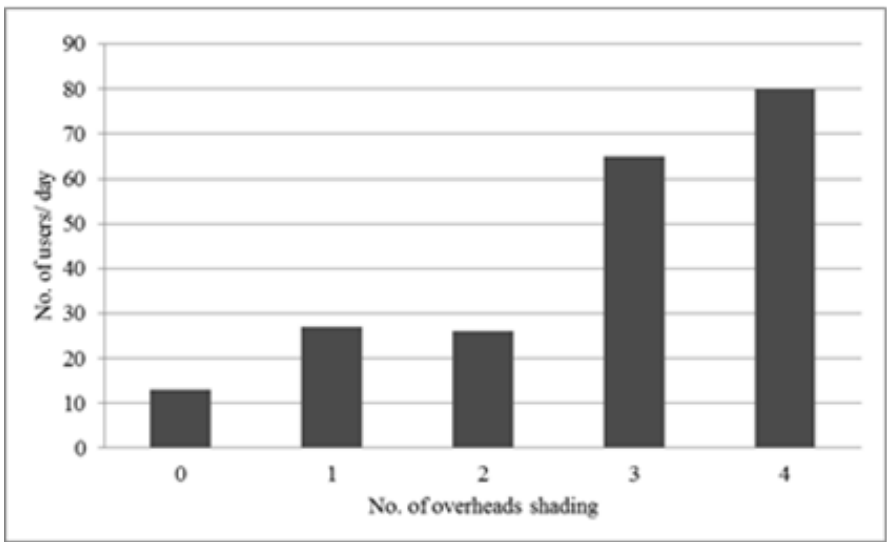

Figure 6(a): Shading devices visitors/day 


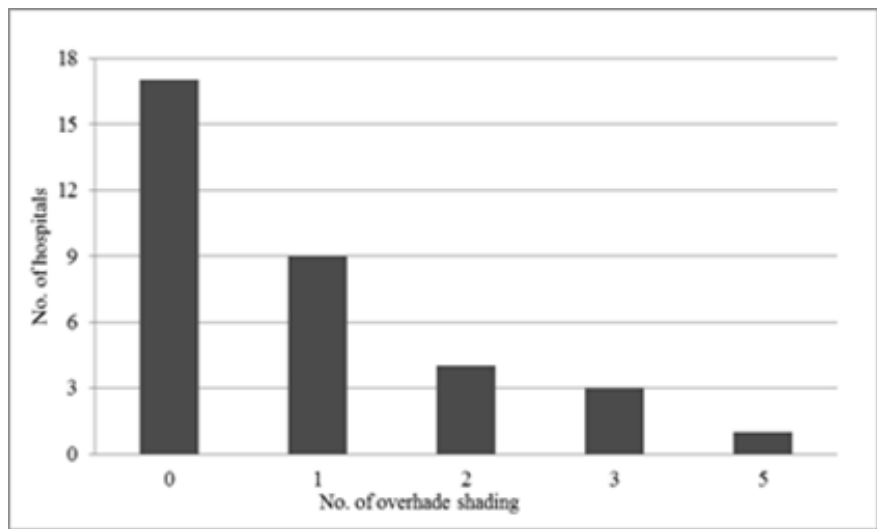

Figure 6(b): Number of shading devices/hospitals

\subsection{Conclusion}

This paper describes a research effort that contributes towards understanding the characters of courtyard designs in Malaysia. The results revealed that courtyards are a frequent architectural footprint applied in the Malaysian hospitals buildings. The footprint of courtyards in the Malaysian hospitals is in the shape of enclosed, open, clustered and multiple. The rectangular enclosed courtyard type was the most common with size ranging between 600 and $900 \mathrm{~m} 2$. Many courtyards were oriented to East-West to avoid direct solar radiation. Some of the courtyards North-South oriented courtyards were enhanced with an increased number of floors from east or west direction to avoid direct solar radiation. It was notable that courtyards with shading devices had more positive effect as more people used it. Shading devices as an extension of the roof were very popular in Malaysian hospital courtyards. Garden was the most popular usage of courtyards in hospitals. An opportunity area of courtyard potential that is currently underutilized is its healing properties. The research has provided a background to support further research and analysis on the impact of courtyard design variants of its performance.

\section{Acknowledgement}

This research is made possible with the financial support provided by the Research Management Institute (RMI), Universiti Teknologi MARA, Malaysia under its Research Intensive Faculty (RIF) funding programme. We therefore thank RMI as well as the Faculty of Architecture, Planning and Surveying for this research opportunity.

\section{References}

Al-Hemiddi, Nasser A., \& Megren Al-Saud, Khalid A. (2001a). The effect of a ventilated interior courtyard on the thermal performance of a house in a hot-arid region. Renewable Energy, 24(3-4), 581-595. 
Al-Hemiddi, Nasser A., \& Megren Al-Saud, Khalid A. (2001b). The effect of a ventilated interior courtyard on the thermal performance of a house in a hot-arid region. Renewable Energy, 24(3-4), 581-595. doi: http://dx.doi.org/10.1016/S0960-1481(01)00045-3

Aldawoud, Abdelsalam. (2008). Thermal performance of courtyard buildings. Energy and Buildings, 40(5), 906-910.

Almhafdy, Abdulbasit, Ibrahim, Norhati, Ahmad, Sabarinah Sh, \& Yahya, Josmin. (2013). Courtyard Design Variants and Microclimate Performance. Procedia - Social and Behavioral Sciences, 101(0), 170-180. doi: http://dx.doi.org/10.1016/j.sbspro.2013.07.190

Berkovic, Sigalit, Yezioro, Abraham, \& Bitan, Arieh. (2012). Study of thermal comfort in courtyards in a hot arid climate. Solar Energy, 86(5), 1173-1186. doi: http://dx.doi.org/10.1016/j.solener.2012.01.010

Edwards, B, Sibley, M., Hakmi, M., \& Land, p. (2006). Courtyard housing: past, present and future: Spon Press.

Flinck, Daren. (2004). Come to the courtyard: Protocols of praising God in the postmodern world. (3124339 D.Min.), Drew University, Ann Arbor. Retrieved from

http://search.proquest.com.ezaccess.library.uitm.edu.my/docview/305178528?accountid=42518 ProQuest Dissertations \& Theses Full Text database.

Kim, Myung-Jun, Yang, Hong-Seok, \& Kang, Jian. (2014). A case study on controlling sound fields in a courtyard by landscape designs. Landscape and Urban Planning, 123(0), 10-20. doi: http://dx.doi.org/10.1016/j.landurbplan.2013.12.001

Meir, Isaac A., Pearlmutter, David, \& Etzion, Yair. (1995). On the microclimatic behavior of two semi-enclosed attached courtyards in a hot dry region. Building and Environment, 30(4), 563-572.

Muhaisen, Ahmed S. (2006). Shading simulation of the courtyard form in different climatic regions. Building and Environment, 41(12), 1731-1741.

Muhaisen, Ahmed S., \& B Gadi, Mohamed. (2006). Shading performance of polygonal courtyard forms. Building and Environment, 41(8), 1050-1059.

Rajapaksha, I., Nagai, H., \& Okumiya, M. (2003). A ventilated courtyard as a passive cooling strategy in the warm humid tropics. Renewable Energy, 28(11), 1755-1778.

Reynolds, J. (2002). Courtyards: aesthetic, social, and thermal delight: Wiley.

Rust, C. (2010). Design for Healthcare. the United States of America: Renee Wilmeth.

Sadafi, Nasibeh, Salleh, Elias, Haw, Lim Chin, \& Jaafar, Zaky. (2011). Evaluating thermal effects of internal courtyard in a tropical terrace house by computational simulation. Energy and Buildings, 43(4), 887-893. doi: http://dx.doi.org/10.1016/j.enbuild.2010.12.009

Safarzadeh, H., \& Bahadori, M. N. (2005). Passive cooling effects of courtyards. Building and Environment, 40(1), 89104.

Tablada, A, Blocken, B, Carmeliet, J, De Troyer, F, \& Verschure, H. (2005). The influence of courtyard geometry on air flow and thermal comfort: CFD and thermal comfort simulations.

Wang, Yiming. (2006). Investigating the application of Chinese classical garden design principles to the revitalization of courtyard houses in Beijing. (MR20550 M.Arch.), Dalhousie University (Canada), Ann Arbor. Retrieved from

http://search.proquest.com.ezaccess.library.uitm.edu.my/docview/304952171?accountid=42518

ProQuest Dissertations \& Theses Full Text database. 